Check for updates

Cite this: RSC Adv., 2020, 10, 40697

Received 18th September 2020

Accepted 4th November 2020

DOI: $10.1039 / \mathrm{d}$ Ora08010a

rsc.li/rsc-advances

\section{A pectin/chitosan/zinc oxide nanocomposite for adsorption/photocatalytic remediation of carbamazepine in water samples $\dagger$}

\begin{abstract}
Olivia A. Attallah (iD * and Mahmoud Rabee
The present study investigates a synergistic adsorption/photodegradation technique catalyzed by a pectin/ chitosan/zinc oxide (Pec/CS/ZnO) nanocomposite for the removal of carbamazepine (CBZ) in aqueous solutions under direct sunlight. The Pec/CS/ZnO nanocomposite was prepared by an inotropic gelation method and was characterized using different techniques. The adsorption/photocatalytic activity of the $\mathrm{Pec} / \mathrm{CS} / \mathrm{ZnO}$ nanocomposite for the remediation of CBZ was optimized using Box-Behnken design under response surface methodology. The examined parameters included the amount of Pec/CS/ZnO nanocomposite $\left(0.25-0.75 \mathrm{~g} \mathrm{~L}^{-1}\right), \mathrm{pH}(4-10)$, and run time for adsorption/photo-irradiation (1-5 hours). The efficiency of CBZ degradation was calculated in terms of changes in CBZ concentration using a validated chromatographic assay. The optimum conditions for the remediation of CBZ were $0.5 \mathrm{~g} \mathrm{~L}^{-1}$ $\mathrm{Pec} / \mathrm{CS} / \mathrm{ZnO}$ nanocomposite, $\mathrm{pH} 4$, and 3 hour run time. Under such conditions, the degradation efficiency of $10 \mathrm{mg} \mathrm{L}^{-1} \mathrm{CBZ}$ was found to be $69.5 \%$ with a rate constant $(k)$ of $0.00737 \mathrm{~min}^{-1}$ and halflife time of $94 \mathrm{~min}$. The efficiency of the Pec/CS/ZnO nanocomposite for CBZ remediation was found to be stable and consistent after three cycles of reuse. The presence of other pharmaceutical contaminants such as acetaminophen in wastewater samples was also investigated. The efficiency of CBZ degradation was not significantly affected by the addition of acetaminophen in a $0-15 \mathrm{mg} \mathrm{L}^{-1}$ concentration range which confirmed the selectivity and efficiency of the proposed method for CBZ degradation and removal.
\end{abstract}

\section{Introduction}

Pharmaceuticals have long saved the lives of millions and lengthened their life spans. Through the years, pharmaceuticals have been able to cure deadly diseases, prevent the occurrence of certain illnesses and improve quality of life. ${ }^{1}$ Nevertheless, despite their success and importance, pharmaceuticals have emerged as rapidly growing environmental contaminants. ${ }^{2}$ Recently, residues of pharmaceutical contaminants have been found in most environmental matrices and they are considered as "compounds of emerging concern". ${ }^{1}$ Pharmaceutical residues have very great potential to harm ecosystems and threaten human health. ${ }^{2}$ Consequently, different analytical techniques, such as UPLC/MS, LC-MS/MS, and GC-MS/MS have been developed to monitor the concentration of these residues in different environmental matrices. ${ }^{1}$ In addition, wastewater treatment plants (WWTPs) were designed to assist in their remediation process but their efficiency was less than $10 \%$ for certain pharmaceuticals. ${ }^{3}$

Pharmaceutical Chemistry Department, Faculty of Pharmacy, Heliopolis University, Cairo - Belbeis Desert Road, El Salam, Cairo 11777,Egypt.E-mail: olivia.adly@hu. edu.eg

$\dagger$ Electronic supplementary information (ESI) available. See DOI: 10.1039/d0ra08010a
Carbamazepine (CBZ) (Fig. 1) is an anticonvulsant drug and is one of these pharmaceuticals described with very poor remediated efficiency by WWTPs. ${ }^{1,2}$ CBZ is a tricyclic neutral compound of lipophilic nature and is utilized in the treatment of trigeminal neuralgia, partial epilepsy and as an adjunct therapy in psychosis. ${ }^{4}$ Various routes of treatment have been proposed to overcome the inefficiency of WWTP in the removal

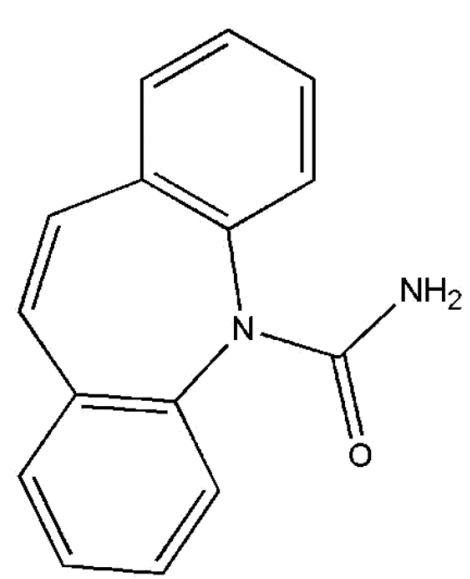

Fig. 1 Chemical structure of carbamazepine (CBZ). 
of CBZ. Such approaches include advanced oxidation, ${ }^{5-10}$ membrane filtration, ${ }^{11-13}$ and ozonation. ${ }^{\text {14-17 }}$

To date, photocatalytic degradation has proven to efficiently degrade several pharmaceuticals from natural-waters and waste-waters. ${ }^{18}$ The process of photocatalysis usually occurs in the presence of a catalyst such as zinc oxide $(\mathrm{ZnO})$ and titanium dioxide $\left(\mathrm{TiO}_{2}\right)$ nanoparticles which have been thoroughly tested and showed very promising results. ${ }^{5,18-25}$

Moreover, it was recently suggested that to treat organic pollutants in waste-waters and natural-waters, multifunctional, advanced materials are required. ${ }^{26}$ In this sense, hybrid organic/ inorganic nanocomposites are of great interest for environmental remediation. Such materials possess multi functionality due to the incorporation of various compounds in their matrices. ${ }^{27}$ Accordingly, these nanocomposites can serve in combined adsorption/photocatalysis processes. The organic portion of the nanocomposite incorporates polymers like chitosan, polyaniline, cellulose, pectin, polyacrylamide and polystyrene. ${ }^{26}$ These polymers act as adsorbents, increase the exposed surface area for remediation and improve the mechanical properties of the inorganic portion of the composite. On the other hand, the inorganic counterpart such as $\mathrm{ZnO}$ and $\mathrm{TiO}_{2}$ is responsible for the composite photocatalytic activity. ${ }^{26}$

Several studies have evaluated the efficiency of organic/ inorganic nanocomposites for the remediation of different contaminants in aqueous solutions. For instance, Gupta et al. fabricated a nanocomposite of pectin $\mathrm{Zr}$ (Iv) seleno-tungstophosphate for synergistic adsorption/photocatalytic remediation of methylene blue and malachite green dyes from aqueous solution. ${ }^{26}$ They were able to reach a photocatalytic degradation percentage of $89.21 \%$ for methylene blue and $79.27 \%$ for malachite green after 3 hours of synergistic adsorption/photoirradiation processes. ${ }^{26}$ Another study evaluated the efficiency of $\mathrm{g}-\mathrm{C}_{3} \mathrm{~N}_{4} / \mathrm{Ag}_{2} \mathrm{CO}_{3}$ hybrid photocatalyst for the remediation of methyl orange dye and found that the hybrid material showed enhanced photocatalytic activity than pure $\mathrm{g}-\mathrm{C}_{3} \mathrm{~N}_{4}$ and $\mathrm{Ag}_{2} \mathrm{CO}_{3}{ }^{28} \mathrm{Fu}$ et al. also demonstrated that the activity of a hybrid photocatalyst of $\mathrm{C}_{3} \mathrm{~N}_{4} / \mathrm{CdS}$ is 20 times higher than those of individual $\mathrm{C}_{3} \mathrm{~N}_{4}$ and CdS for the degradation of methyl orange. ${ }^{29}$ Yan et al. studied the activity of $\mathrm{g}-\mathrm{C}_{3} \mathrm{~N}_{4}-\mathrm{TaON}$ photocatalyst for the photodegradation of rhodamine $\mathrm{B}$ and found that the new hybrid photocatalyst has higher catalytic activity than the single-phase $\mathrm{g}-\mathrm{C}_{3} \mathrm{~N}_{4}$ or TaON. ${ }^{30}$

The main objective of this work is to study a synergetic adsorption/photocatalysis technique in the presence of an organic/inorganic nanocomposite for the remediation of CBZ as model pharmaceutical contaminant. Based on surveyed literature, the photo-degradation of CBZ is well documented and is a subject of massive research. Photocatalysis is considered one of the efficient techniques for the removal of CBZ and the presence of nanoparticles as $\mathrm{TiO}_{2}$ and $\mathrm{ZnO}$ enhances the photocatalytic process and shortens the time required for degradation. ${ }^{18-20,22,23}$

Here we focus on the synthesis of a novel organic/inorganic; pectin/chitosan/ZnO (Pec/CS/ZnO) nanocomposite having chitosan and pectin polymers acting as adsorbents for CBZ while inorganic nano $\mathrm{ZnO}$ is responsible for the photocatalytic degradation of CBZ. The incorporation of nano $\mathrm{ZnO}$ into pectin and chitosan to form nanocomposite is expected to impart unique functionalities to the prepared nanocomposite and improve its efficiency in CBZ remediation. The effect of selected parameters; amount of $\mathrm{Pec} / \mathrm{CS} / \mathrm{ZnO}$ nanocomposite, $\mathrm{pH}$ and adsorption/photo-irradiation time (run time) on the efficiency of CBZ degradation has been studied and optimized using BoxBehnken design. The efficacy of presence of other contaminants in wastewaters on the proposed remediation technique was also evaluated and acetaminophen was selected as model contaminant.

To the best of our knowledge, there are no studies that discuss the development and optimization of a synergistic adsorption/photocatalytic technique using Pec/CS/ZnO nanocomposite for the efficient remediation of organic pharmaceutical contaminants as CBZ.

\section{Experimental}

\subsection{Materials}

Zinc sulphate heptahydrate $\left(\mathrm{ZnSO}_{4} \cdot 7 \mathrm{H}_{2} \mathrm{O}\right)$ and pectin from the rind of citrus or apple (galacturonic acid $\geq 74.0 \%$ ) were obtained from Fisher Scientific (USA). Chitosan of low molecular weight (89.9\% degree of dealkylation) was purchased from (Primex ehf, Chitoclear, Iceland), calcium chloride dihydrate $\left(\mathrm{CaCl}_{2} \cdot 2 \mathrm{H}_{2} \mathrm{O}\right)$ was obtained from Sigma Aldrich Co. (USA). Pharmaceutical grade carbamazepine (CBZ) and acetaminophen were supplied by Novartis Pharmaceuticals (Cairo, Egypt) and certified to have $99.7 \%$ purity. HPLC grade acetonitrile was purchased from Honeywell (Germany) and HPLC grade water was obtained from LiChrosolv (Germany).

\subsection{Preparation of $\mathrm{Pec} / \mathrm{CS} / \mathrm{ZnO}$ nanocomposite}

2.2.1. Preparation of $\mathrm{ZnO}$ nanoparticles. $\mathrm{ZnO}$ nanoparticles were prepared using a direct precipitation method proposed by Ghorbani et al. with slight modification. ${ }^{31}$ Briefly, aqueous solution $(0.2 \mathrm{M})$ of zinc sulphate $\left(\mathrm{ZnSO}_{4} \cdot 7 \mathrm{H}_{2} \mathrm{O}\right)$ and $(0.4 \mathrm{M})$ solution of sodium hydroxide $(\mathrm{NaOH})$ were prepared in distilled water. The $\mathrm{NaOH}$ solution was slowly added into zinc sulphate solution under vigorous stirring at room temperature until $\mathrm{pH}$ reached 9. The mixture was kept under stirring for 2 hours and the white precipitate was then separated via centrifugation at $5000 \mathrm{rpm}$ for $15 \mathrm{~min}$ and washed three times with distilled water. The obtained product was then calcined at $250{ }^{\circ} \mathrm{C}$ for 3 hours.

2.2.2. Preparation of $\mathrm{Pec} / \mathrm{CS} / \mathrm{ZnO}$ nanocomposite. Inotropic gelation technique was used to prepare Pec/CS/ZnO nanocomposite at room temperature. ${ }^{32}$ To $60 \mathrm{~mL}$ Pec solution $(0.44 \%(\mathrm{w} / \mathrm{v})), 0.5 \mathrm{~g}$ of the prepared $\mathrm{ZnO}$ nanoparticles was added and left under magnetic stirring for $30 \mathrm{~min}$ to ensure homogenous dispersion. CS solution $(2 \%(\mathrm{w} / \mathrm{v}))$ was prepared in $1 \%$ acetic acid $(\mathrm{w} / \mathrm{v})$, while calcium chloride $\left(\mathrm{CaCl}_{2}\right)$ solution $(0.5 \%(\mathrm{w} / \mathrm{v}))$ was prepared in distilled water. $15 \mathrm{~mL}$ of $(0.28 \%(\mathrm{w} /$ v)) $\mathrm{CS}$ and $(0.064 \%(\mathrm{w} / \mathrm{v})) \mathrm{CaCl}_{2}$ mixture solution was slowly added to the $60 \mathrm{~mL} \mathrm{Pec/ZnO}$ dispersion. The $\mathrm{pH}$ was adjusted at 
5.5 and the mixture solution was left under stirring for $60 \mathrm{~min}$. The prepared Pec/CS/ZnO nanocomposite was then isolated via centrifugation at $5000 \mathrm{rpm}$ for $20 \mathrm{~min}$, followed by washing several times in distilled water. Finally, Pec/CS/ZnO nanocomposite was dispersed in distilled water and dried at $50{ }^{\circ} \mathrm{C}$ for 72 hours.

\subsection{Adsorption/photocatalytic experiments of CBZ}

The adsorption/photocatalytic experiments were carried out on CBZ as model pharmaceutical contaminant in aqueous samples using batch process. The initial concentration of CBZ was kept at $10 \mathrm{mg} \mathrm{\textrm {L } ^ { - 1 }}$. Determined amounts of $\mathrm{Pec} / \mathrm{CS} / \mathrm{ZnO}$ nanocomposite were added to the test samples and $\mathrm{pH}$ was adjusted using 0.1 M hydrochloric acid and sodium hydroxide solutions. Samples were then placed in a glass chamber jacketed with thermostat water circulation to maintain constant temperature at $25{ }^{\circ} \mathrm{C}$ and were exposed directly to sunlight to allow a synergistic adsorption/photocatalysis process to occur. After the specified times samples were removed, filtered and the concentration of CBZ in the supernatant solutions was determined via a validated chromatographic assay.

The efficiency of degradation (\%) was calculated using eqn (1). ${ }^{33}$

$$
\text { Degradation }(\%)=\frac{C_{0}-C_{t}}{C_{0}} \times 100
$$

The rate of photocatalytic degradation of $\mathrm{CBZ}$ was then tested against pseudo first order kinetic model using eqn (2): ${ }^{34}$

$$
\log \frac{C_{0}}{C_{t}}=\frac{k_{\mathrm{app}}}{2.303} t
$$

where $k_{\text {app }}$ is the apparent rate constant, $C_{0}$ and $C_{t}$ are the concentrations of CBZ before treatment and at time $t$, respectively and the half life time as $t_{1 / 2}=\frac{0.693}{k} .^{34}$

\subsection{Chromatographic analysis}

Stock standard solutions of both $\mathrm{CBZ}$ and acetaminophen $\left(0.1 \mathrm{mg} \mathrm{mL}{ }^{-1}\right)$ were prepared in $100 \mathrm{~mL}$ methanol. Aliquots of stock solutions were withdrawn and diluted with distilled water to prepare working standard solutions of 1 to $100 \mu \mathrm{g} \mathrm{mL}^{-1}$ concentration range. HPLC chromatographic separation was achieved using a HiQsil C18 HS column $(250 \times 4.6 \mathrm{~mm}, 5 \mathrm{~mm})$ on HPLC system model 1100 (Agilent Technologies, USA) with variable wavelength detector and an auto sampler. Analyses were performed using isocratic elution with a mobile phase of water : acetonitrile (60\% : 40\% v/v, $1.5 \mathrm{~mL} \mathrm{~min}^{-1}$ ) at ambient temperature and $20 \mu \mathrm{L}$ injection volume. Detection was carried out at $284 \mathrm{~nm}$ for CBZ and $240 \mathrm{~nm}$ for acetaminophen using variable wavelength detector. Calibration curves were plotted over concentration range of $1-25 \mu \mathrm{g} \mathrm{mL}{ }^{-1}$ for $\mathrm{CBZ}$ and acetaminophen and validation parameters were calculated according to ICH-guidelines.
Table 1 Variables and levels in Box-Behnken experimental design for CBZ degradation and removal

\begin{tabular}{llll}
\hline & Level & \\
\cline { 2 - 4 } & -1 & 0 & 1 \\
\hline Independent variables & 0.25 & 0.50 & 0.75 \\
$X_{1}:$ amount of Pec/CS/ZnO $\left(\mathrm{g} \mathrm{L}^{-1}\right)$ & 4 & 7 & 10 \\
$X_{2}: \mathrm{pH}$ & 1 & 3 & 5 \\
$X_{3}:$ run time (hour) & &
\end{tabular}

\subsection{Design of experiment}

Three-factor, three-level Box-Behnken design (BBD) (Design Expert, trial version 10.0.5.0, Stat-Ease Inc., Minneapolis, MN) was implemented for the optimization of CBZ remediation using Pec/CS/ZnO nanocomposite. The design involved fifteen experimental runs with three replicated center points. The chosen independent factors were the amount of Pec/CS/ZnO nanocomposite $\left(X_{1}\right), \mathrm{pH}\left(X_{2}\right)$, and run time $\left(X_{3}\right)$ and were varied at three levels. The response or dependent variable studied was taken as the efficiency of CBZ degradation (\%). The independent factors and ranges for each independent factor were based on available literature and preliminary experiments. Nominated ranges are shown in (Table 1). Other parameters like temperature and agitation speed were kept constant in all experiments.

\subsection{Reusability of $\mathrm{Pec} / \mathrm{CS} / \mathrm{ZnO}$ nanocomposite}

To test the degradation stability and reusability of $\mathrm{Pec} / \mathrm{CS} / \mathrm{ZnO}$ nanocomposite, the adsorption/photocatalytic degradation experiments were carried out in triplicate under the same conditions $\left(0.5 \mathrm{~g} \mathrm{~L}^{-1} \mathrm{Pec} / \mathrm{CS} / \mathrm{ZnO}\right.$ nanocomposite, $\mathrm{pH} 4$ and 3 hour run time) on $10 \mathrm{mg} \mathrm{L}^{-1} \mathrm{CPZ}$ samples. After each use, Pec/CS/ZnO nanocomposite were placed in a beaker of $50 \mathrm{~mL} 5 \%(\mathrm{v} / \mathrm{v})$ methanol/HCl for one hour to remove any adsorbed CBZ. The solvent was then decanted and Pec/CS/ZnO nanocomposite was dried in an oven at $60{ }^{\circ} \mathrm{C}$ for 2 hours. The nanocomposite was reused for two more times for CBZ adsorption/photodegradation, in the aforementioned conditions.

\subsection{Application on synthetic wastewater samples}

The efficiency of the proposed synergistic adsorption/ photocatalytic method for the remediation of CBZ in aqueous solutions in the presence of other contaminants was evaluated. Synthetic wastewater samples were prepared in distilled water and adsorption/photocatalytic experiments were performed

Table 2 Composition of synthetic wastewater samples

\begin{tabular}{lll}
\hline Samples $(\mathrm{S})$ & $\begin{array}{l}\text { CBZ concentration } \\
\left(\mathrm{mg} \mathrm{L}^{-1}\right)\end{array}$ & $\begin{array}{l}\text { Acetaminophen concentration } \\
\left(\mathrm{mg} \mathrm{L}^{-1}\right)\end{array}$ \\
\hline S1 & 10 & 0 \\
S2 & 10 & 10 \\
S3 & 10 & 15
\end{tabular}


using the optimized conditions obtained from BBD. The synthetic wastewater samples were spiked with CBZ and acetaminophen as model pharmaceutical contaminants in the wastewater samples. Table 2 shows the composition of the synthetic wastewater samples. Pec/CS/ZnO nanocomposite $\left(0.5 \mathrm{~g} \mathrm{~L}^{-1}\right)$ was added to the synthetic wastewater samples and $\mathrm{pH}$ was adjusted at 4 . Samples were then added to the glass chamber where temperature was kept constant at $25{ }^{\circ} \mathrm{C}$. The synergistic adsorption/photocatalytic process was performed for 3 hours in direct sunlight. Samples were then collected, centrifuged and the concentrations of CBZ and acetaminophen left in the supernatant solutions of each sample were determined by the validated chromatographic assay.

\section{Results and discussion}

\subsection{Characterization of Pec/CS/ZnO nanocomposite}

Transmission electron microscopy (TEM) on Tecani G20, FEI transmission electron microscope (USA) and scanning electron microscopy (SEM) on a Zeiss Instrument (Germany) were used for the morphological study of $\mathrm{Pec} / \mathrm{CS} / \mathrm{ZnO}$ nanocomposite. Fig. 2(a) shows the TEM image of $\mathrm{ZnO}$ nanoparticles prepared by precipitation method. In this figure, the particles showed a formation of clusters having an average diameter of $30 \mathrm{~nm}$. Fig. 2(b) shows the SEM image of Pec/CS/ZnO nanocomposite
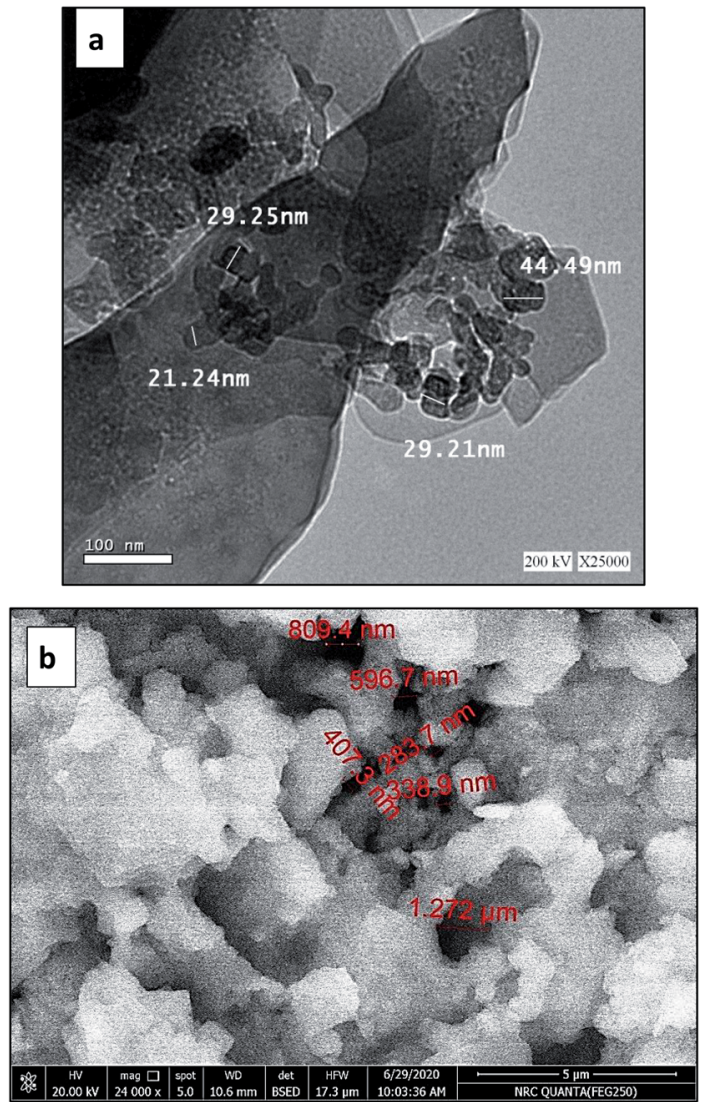

Fig. 2 (a) TEM image of $\mathrm{ZnO}$ nanoparticles, (b) SEM image of Pec/CS/ $\mathrm{ZnO}$ nanocomposite.

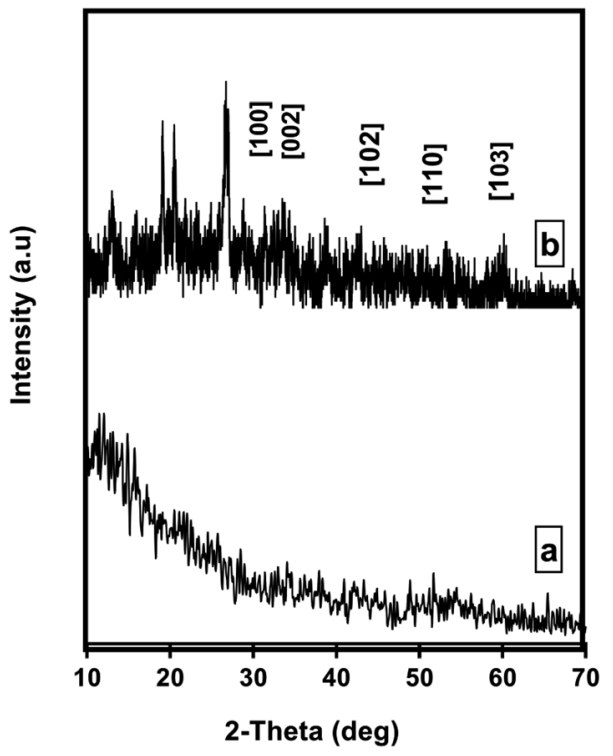

Fig. 3 XRD pattern of (a) Pec/CS and (b) Pec/CS/ZnO nanocomposites.

consisting of particles which are arranged as porous, granularlike structure. The particle size of $\mathrm{Pec} / \mathrm{CS} / \mathrm{ZnO}$ nanocomposite was in the range of $300-800 \mathrm{~nm}$ in diameter.

Crystallographic properties of Pec/CS and Pec/CS/JO nanocomposites were evaluated using X-ray diffraction (XRD) over a $2 \theta$ range from 10 to $70^{\circ}(2 \theta)$ on a Bruker AXS D8 (Germany). As shown in Fig. 3(a), XRD pattern of Pec/CS nanocomposite showed a broad typical hump of amorphous material indicating the noncrystalline nature of the nanocomposite. The XRD pattern of Pec/CS/ZnO nanocomposite demonstrated the presence of diffraction peaks that were indexed to those of hexagonal ZnO (JCPDS card, no. 80-0075). Noticeably the peaks were somehow broadened which suggested that Pec/CS/ZnO nanocomposite was also amorphous in nature proving the interaction between ZnO NPs and Pec/CS composite.

Analysis of the chemical composition of Pec/CS/ZnO nanocomposite was implemented by Energy Dispersion X-ray technique (EDX) in a Zeiss Instrument (Germany). Fig. 4 reveals the presence of $\mathrm{C}, \mathrm{O}, \mathrm{N}$ and $\mathrm{Zn}$ elements in $\mathrm{Pec} / \mathrm{CS} / \mathrm{ZnO}$

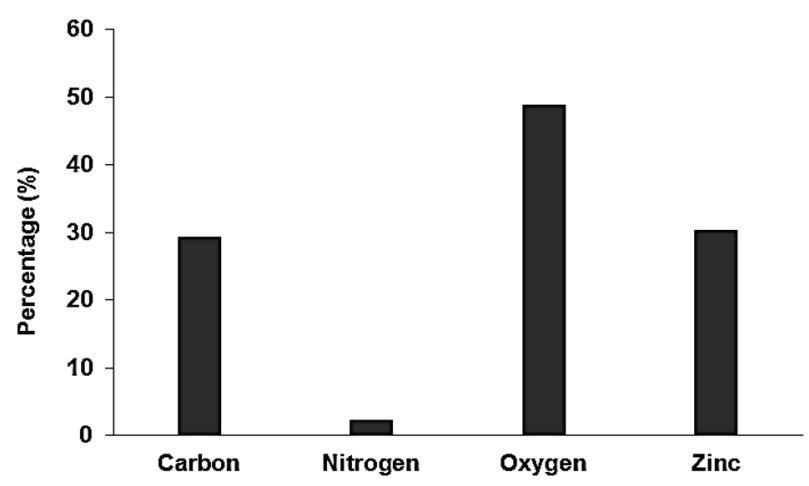

Fig. 4 EDX analysis of Pec/CS/ZnO nanocomposite. 


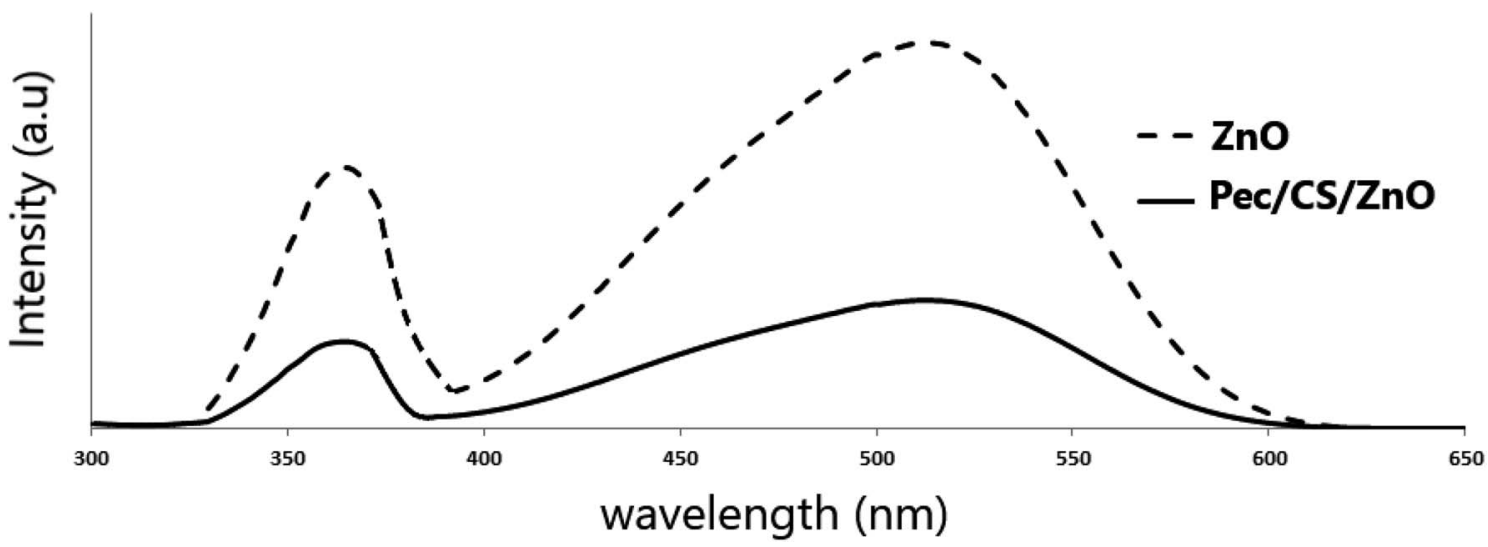

Fig. 5 Photoluminescence spectra of ZnO NPs and Pec/CS/ZnO nanocomposite.

nanocomposite with a $30 \% \mathrm{Zn}$ element proportion in the tested samples. Such results indicate the incorporation and significant dispersion of ZnO NPs within Pec/CS composite matrix.

The photoluminescence spectra of ZnO NPs and Pec/CS/ZnO nanocomposites obtained at the excitation wavelength of $325 \mathrm{~nm}$ at room temperature using PerkinElmer LS 55 Luminescence spectrometer are demonstrated in Fig. 5. The emission peak at $365 \mathrm{~nm}$ is ascribed for electron transition between shallow donor level of $\mathrm{Zn}$ interstitial to top level of the valence band..$^{35}$ The emission band at $515 \mathrm{~nm}$ is due to the recombination of photo generated holes by electrons in singly occupied oxygen vacancies. ${ }^{35}$ Noticeably, the luminescence properties of $\mathrm{Pec} / \mathrm{CS} / \mathrm{ZnO}$ nanocomposite have been suppressed compared to pure $\mathrm{ZnO}$ which could be due to the transition effect of higher
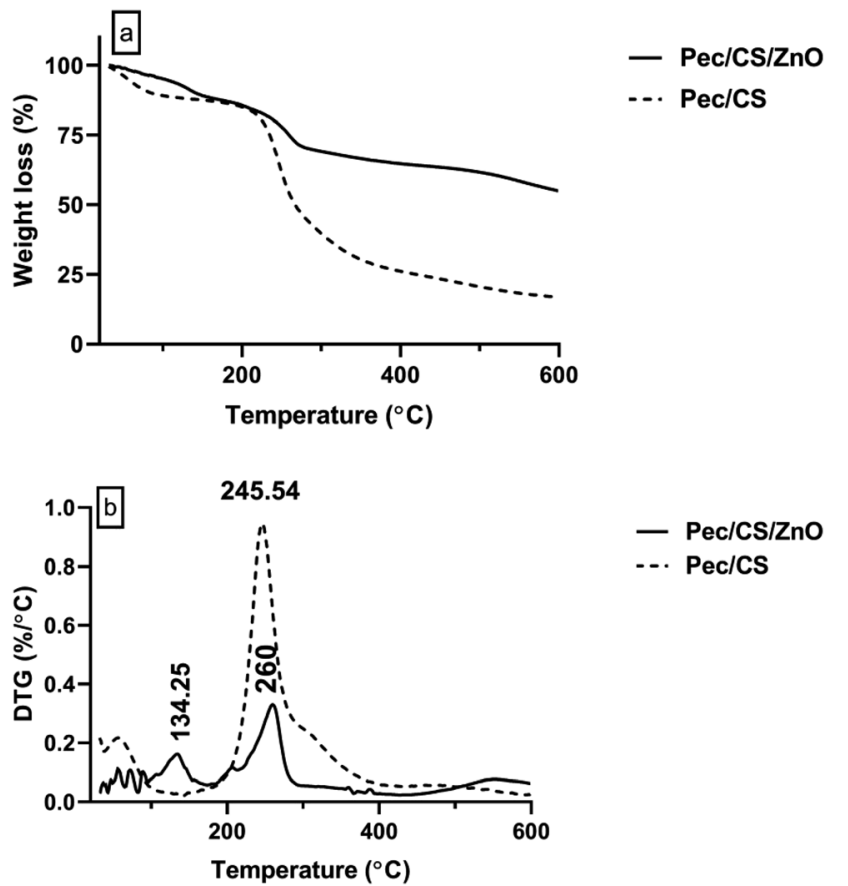

Fig. 6 (a) TGA and (b) DTG of Pec/CS and Pec/CS/ZnO nanocomposite. energy and charge between Pec/CS and $\mathrm{ZnO}^{36}$ The band gap energy of Pec/CS/ZnO nanocomposite was also slightly shifted which could be attributed to the interaction between Pec/CS and $\mathrm{ZnO}$ in the nanocomposite. ${ }^{36}$

Thermogravimetric analysis was performed on a Q50 Thermogravimetric Analyzers, TA, USA, in the temperature range 20$600{ }^{\circ} \mathrm{C}$ under $\mathrm{N}_{2}$ atmosphere. Fig. 6 shows the results of thermogravimetric analysis (TGA and DTG) of Pec/CS and Pec/CS/ ZnO nanocomposites. A clear difference can be observed between the two composites thermograms indicating the successful incorporation of $\mathrm{ZnO}$ nanoparticles within Pec/CS composite matrix. In the DTG curve of $\mathrm{Pec} / \mathrm{CS} / \mathrm{ZnO}$ nanocomposite, an initial peak at $134.25{ }^{\circ} \mathrm{C}$ related to moisture evaporation can be observed with up to $20 \%$ weight loss. A second strong peak starting at $220^{\circ} \mathrm{C}$ reaching its maximum at $260^{\circ} \mathrm{C}$ was also found on the DTG curve. The appearance of this peak is attributed to the thermal de-polymerization of Pec and CS chains in the nanocomposite. Noticeably, there was a $15{ }^{\circ} \mathrm{C}$ temperature difference for the appearance of this depolymerization peak between Pec/CS/ZnO nanocomposite and Pec/CS composite. Such results indicated that the de-polymerization process was hindered to some degree due to the presence of strong interactions between Pec/CS and ZnO molecules. ${ }^{27}$

\subsection{Chromatographic analysis}

Different chromatographic conditions were studied to get the optimum separation pattern of CBZ and acetaminophen. Isocratic elution with a mobile phase of water:acetonitrile $60 \%: 40 \% \mathrm{v} / \mathrm{v}$ was found to be the most efficient for separation purposes. The run time was $6.5 \mathrm{~min}$, with flow rate of $1.5 \mathrm{~mL} \min ^{-1}$. As shown in Fig. 7, the retention times were found to be 2.7 and $4.9 \mathrm{~min}$ for acetaminophen and CBZ, respectively. System suitability parameters were also calculated as demonstrated in Table 3 and validation parameters performed per ICH guidelines are summarized in Table 4. The regression equations obtained from the chromatographic assay were used to calculate the concentrations of CBZ and acetaminophen throughout the whole study. 


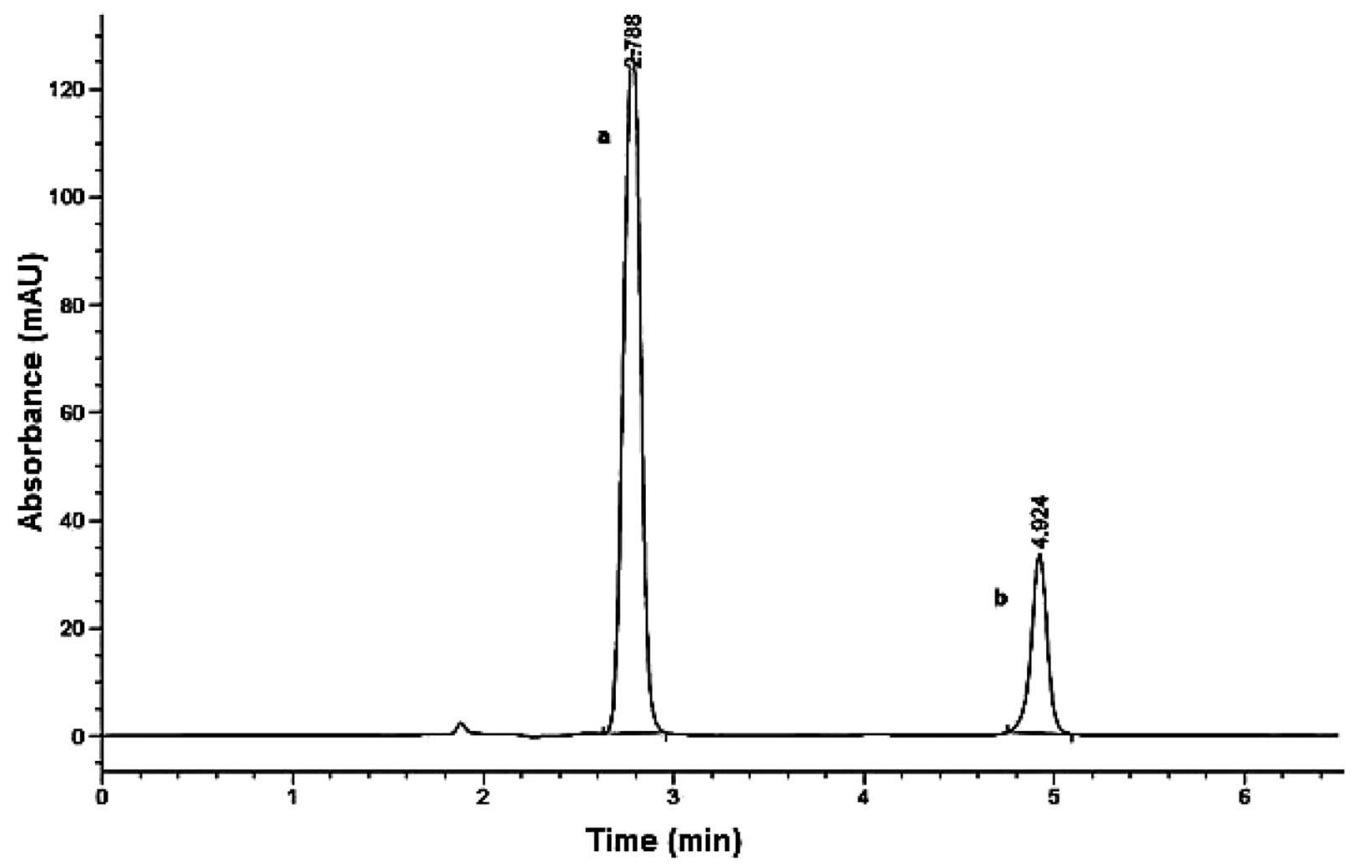

Fig. 7 HPLC chromatogram of (a) acetaminophen at retention time $=2.7 \mathrm{~min}$ and (b) carbamazepine $(\mathrm{CBZ})$ at retention time $=4.9 \mathrm{~min}$.

Table 3 System suitability tests for chromatographic method for the simultaneous determination of CBZ and acetaminophen in their mixture

\begin{tabular}{llll}
\hline & Obtained value & & \\
\cline { 2 - 4 } Parameters & Carbamazepine & Acetaminophen & Reference value \\
\hline Retention time $\left(t_{\mathrm{R}}\right)$ & 4.924 & 2.788 & $T \leq 2$ \\
Symmetry factor $\left(A_{\mathrm{s}}\right)$ & 1 & 1.1 & $N \geq 2000$ \\
Theoretical number plates $(N)$ & 50094 & 12288 & 1.534 \\
Capacity factor $(K)$ & 3.476 & & $R_{\mathrm{s}} \geq 1.5$ \\
Resolution $\left(R_{\mathrm{s}}\right)$ & 22.65 & & $\alpha>1$
\end{tabular}

\subsection{Adsorption/photocatalytic experiments of CBZ}

3.3.1. Experimental design results. The efficiency of $\mathrm{CBZ}$ degradation was analyzed using response surface methodology to evaluate the effects of the studied variables and determine

Table 4 Chromatographic method validation for the determination of laboratory prepared standards of CBZ and acetaminophen

\begin{tabular}{lll}
\hline Item & CBZ & Acetaminophen \\
\hline Retention time & $4.92 \mathrm{~min}$ & $2.78 \mathrm{~min}$ \\
Wavelength of detection & $284 \mathrm{~nm}$ & $240 \mathrm{~nm}$ \\
Range of linearity & $2-25 \mu \mathrm{g} \mathrm{mL}$ & $2-25 \mu \mathrm{g} \mathrm{mL} \mathrm{m}^{-1}$ \\
Regression equation & $A=41.5 C+2.0991$ & $A=52.899 C+1.9322$ \\
Regression coefficient $\left(r^{2}\right)$ & 0.9997 & 0.9996 \\
LOD $\left(\mu \mathrm{g} \mathrm{mL}^{-1}\right)$ & 0.593 & 0.533 \\
LOQ $\left(\mu \mathrm{g} \mathrm{mL}^{-1}\right)$ & 1.797 & 1.615 \\
Accuracy mean $\pm \mathrm{SD}$ & $99.66 \pm 0.54$ & $100.84 \pm 0.7045$ \\
& & \\
Precision & & $0.08-0.29$ \\
Intraday \% RSD $(n=9)$ & $0.33-0.77$ & $0.05-0.46$ \\
Interday \% RSD $(n=9)$ & $0.28-0.70$ &
\end{tabular}

the optimized operating conditions for the remediation process. An experimental design plan was developed for the selected variables and the experimental runs constituted the variation of these variables based on the proposed design. The efficiency of CBZ degradation (\%) after each run was determined and presented as response for the run as summarized in Table 5. Different regression models were fitted to the response data to test for the best fitting model and evaluate the significance of the effect of the studied variables.

Table 6 demonstrates the relation between the efficiency of CBZ degradation $(Y)$ and the studied variables; amount of Pec/ $\mathrm{CS} / \mathrm{ZnO}$ nanocomposite $\left(X_{1}\right), \mathrm{pH}\left(X_{2}\right)$ and run time $\left(X_{3}\right)$. Based on the obtained results, the chosen model to explain CBZ remediation process was the quadratic model. The coefficients of the quadratic equation indicated that the amount of Pec/CS/ $\mathrm{ZnO}$ nanocomposite and the run time together with their interactions had positive effects on the efficiency of CBZ degradation. The increase in $\mathrm{pH}$ value showed a negative effect on the remediation process while its interactions with both the amount of Pec/CS/ZnO nanocomposite and the run time had 
Table 5 Experimental matrix and observed response for CBZ in BBD

\begin{tabular}{lllll}
\hline & \multicolumn{2}{l}{ Independent variable } & & \multicolumn{2}{l}{ Dependent variable } \\
\cline { 2 - 3 } Run & & & & $Y$ \\
& $X_{1}\left(\mathrm{~g} \mathrm{~L}^{-1}\right)$ & $X_{2}$ & $X_{3}$ (hour) & \\
\hline 1 & 0.5 & 7 & 3 & 67.88 \\
2 & 0.25 & 7 & 5 & 33 \\
3 & 0.5 & 10 & 5 & 66.80 \\
4 & 0.75 & 7 & 5 & 59.10 \\
5 & 0.5 & 7 & 3 & 68.00 \\
6 & 0.5 & 7 & 3 & 68.50 \\
7 & 0.5 & 4 & 5 & 58.18 \\
8 & 0.25 & 4 & 3 & 52.00 \\
9 & 0.75 & 10 & 3 & 53.50 \\
10 & 0.5 & 10 & 1 & 47.18 \\
11 & 0.75 & 4 & 3 & 55.50 \\
12 & 0.25 & 7 & 1 & 46.50 \\
13 & 0.5 & 4 & 1 & 62.20 \\
14 & 0.75 & 7 & 1 & 30.88 \\
15 & 0.25 & 10 & 3 & 47.30 \\
& & & & \\
\hline
\end{tabular}

positive coefficient values. Such results indicated that the amount of Pec/CS/ZnO nanocomposite and the run time had more significant effects on CBZ degradation than that of $\mathrm{pH}$. Consequently, it can be concluded that the amount of Pec/CS/ $\mathrm{ZnO}$ nanocomposite and the run time are the most effective variables in CBZ remediation followed by $\mathrm{pH}$.

A sequential test was performed to test the adequacy of the quadratic model to describe CBZ remediation process. A high $F$ value of 2765.5 was obtained for the quadratic model indicating the effectiveness of the proposed model to explain the studied response. High coefficient of determination $\left(R^{2}=0.9998\right)$ was also obtained for the CBZ remediation process and the adjusted $R^{2}$ value (0.9996) was in close agreement with the predicted one $\left(R^{2}=0.9983\right)$.

To determine the significance of the quadratic model at a confidence interval of $95 \%$, analysis of variance (ANOVA) was performed. As shown in Table 6 , the obtained probability value ( $p$ value) of the selected model was less than 0.05 ( $p$-value $<0.0001$ ) indicating that the studied response was in good fit with the quadratic model. In addition, the lack of fit of the studied response was non-significant having a $p$-value greater than $0.1(p$-value $=$ $0.6874)$. Such result is highly desirable as it conclude the suitability of the chosen model to discuss the studied response.
Moreover, the experimental values for the efficiency of CBZ degradation were compared with the predicted values proposed by the quadratic model to evaluate the correlation between them. As shown in Fig. S1. $\dagger$ The plots of the predicted and experimental values were more than $95 \%$ coherent. Such coherence indicates the good correlation between the experimental and predicted values and the ability of the studied variables to provide a good prediction for the CBZ remediation process.

3.3.2. Response surface analysis. Response surface analysis was performed and presented using contour and 3-D plots to estimate the effects of combinations of the studied variables on the efficiency of CBZ degradation. The dependency of CBZ degradation on $\mathrm{pH}$ and the amount of $\mathrm{Pec} / \mathrm{CS} / \mathrm{ZnO}$ nanocomposite is illustrated in Fig. 8. The effect of pH was consistent at high and low levels of Pec/CS/ZnO nanocomposite where the maximum percentage of $\mathrm{CBZ}$ degradation was observed at $\mathrm{pH} 4$. Such result indicates that CBZ remediation process is favored at low pHs where the adsorption of CBZ $\left(\mathrm{p} K_{\mathrm{a}}=13.9\right)$ on Pec/CS/ $\mathrm{ZnO}$ composite (point of zero charge 2.5 (data not shown)) is maximal and suggested to occur through charge forces in aqueous solution. Thus, with the increase of CBZ adsorption on $\mathrm{Pec} / \mathrm{CS} / \mathrm{ZnO}$ nanocomposite, the process of CBZ photodegradation was more facilitated. ${ }^{18}$ The amount of Pec/CS/ ZnO nanocomposite also had a significant effect on the remediation process at $\mathrm{pH} 4$. An increase in the nanocomposite amount resulted in an increase in CBZ degradation reaching its maximum at $0.5 \mathrm{~g} \mathrm{~L}^{-1}$ nanocomposite and then CBZ degradation started to decrease with further increase in the nanocomposite amount. Such behavior could be attributed to the rapid agglomeration of the nanocomposite at elevated concentrations which led to a reduced ability of effective CBZ adsorption on the nanocomposite surface. Thus the rate of degradation reaction was decreased due to the decrease in the production of positive electron-hole and oxidizer radicals. ${ }^{37}$ Another explanation for such decrease in the efficiency of CBZ degradation could be due to the fact that very high concentrations of Pec/CS/ZnO nanocomposite produced large amounts of hydroxyl radicals causing more degradation of CBZ. The increase in CBZ degradation led to the production of large amounts of by-products that deposited on the surface of the nanocomposite resulting in an accelerated deactivation of the photocatalytic activity. ${ }^{38}$

Table 6 Statistical analysis of measured responses for CBZ degradation and removal

\begin{tabular}{lllll}
\hline Fitting model & Factors & Coefficient & $p$-Value & ANOVA \\
\hline Degradation efficiency $(Y)$ & Intercept & 68.13 & & $F=2765.5, R^{2}=0.9994$, model $p$-value $<0.0001, p$-value of lack of fit $=0.6874$ \\
& $X_{1}$ & 2.52 & $<0.0001$ & \\
$X_{2}$ & -1.64 & $<0.0001$ \\
$X_{3}$ & 3.79 & $<0.0001$ \\
$X_{1} X_{2}$ & 0.68 & 0.0050 \\
$X_{1} X_{3}$ & 10.43 & $<0.0001$ \\
$X_{2} X_{3}$ & 5.91 & $<0.0001$ \\
$X_{1}{ }^{2}$ & -16.14 & $<0.0001$ \\
$X_{2}{ }^{2}$ & 0.085 & 0.5910 \\
$X_{3}{ }^{2}$ & -9.62 & $<0.0001$
\end{tabular}




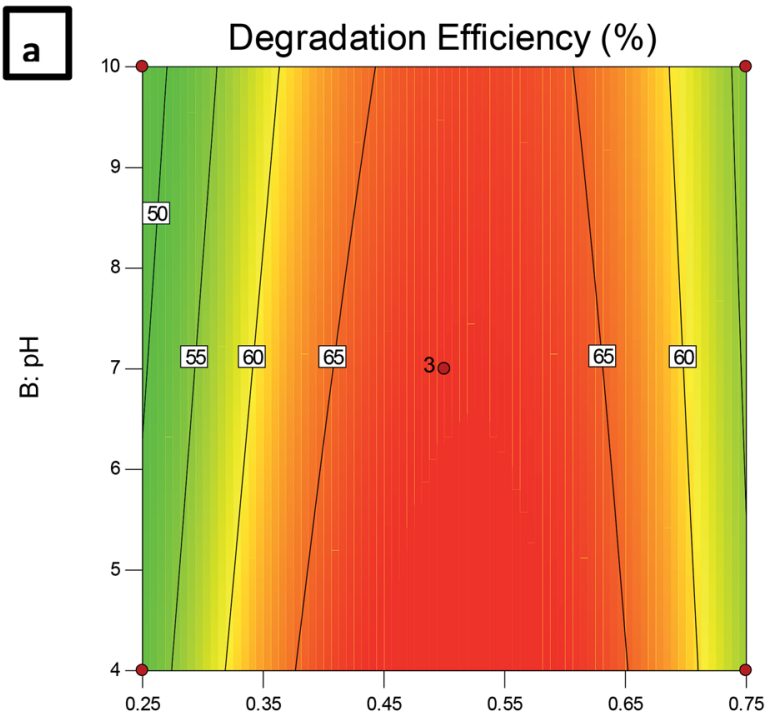

A: Pec/CS/ZnO amount (g/L)

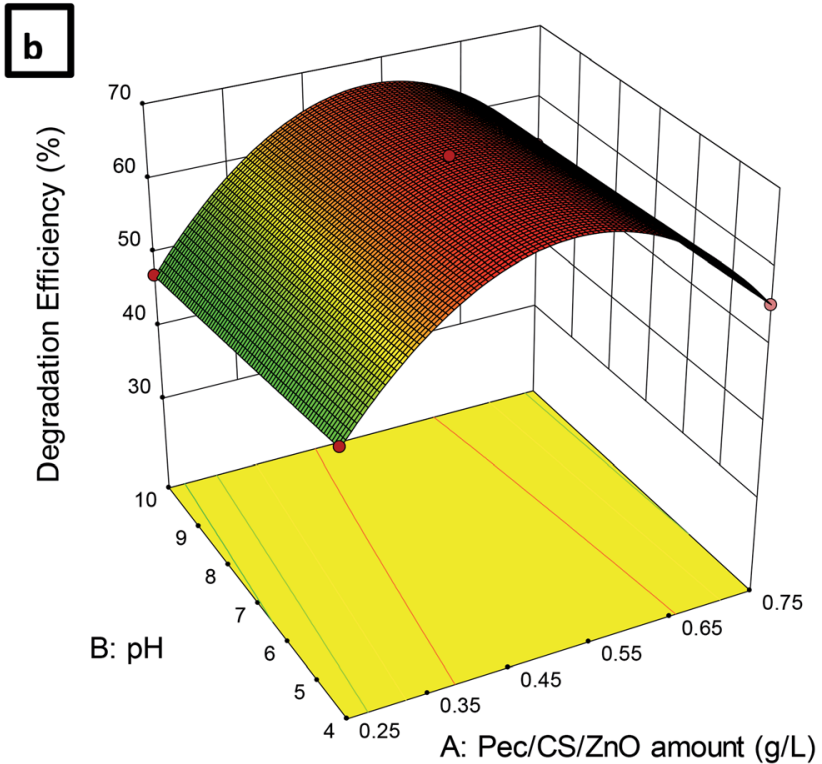

Fig. 8 (a) Contour plot and (b) 3D plot showing the effect of Pec/CS/ $\mathrm{ZnO}$ amount and $\mathrm{pH}$ on $\mathrm{CBZ}$ degradation efficiency.

The dependence of CBZ remediation on the amount of Pec/ $\mathrm{CS} / \mathrm{ZnO}$ nanocomposite and run time is shown in Fig. 9. The highest percentage of CBZ degradation was observed at $0.5 \mathrm{~g} \mathrm{~L}^{-1}$ nanocomposite and 3 hour run time. Further increase in the levels of both variables did not significantly improve the CBZ remediation process which indicated that an equilibrium situation was attained after 3 hours of treatment.

Fig. 10 shows the dependence of CBZ degradation on $\mathrm{pH}$ and run time. It can be observed that the efficiency of CBZ degradation was maximal at $\mathrm{pH} 4$ and decreased with the increase of $\mathrm{pH}$ at all-time intervals. In addition, the increase in the time factor enhanced the CBZ remediation process up to a certain limit where no further increase in CBZ degradation was

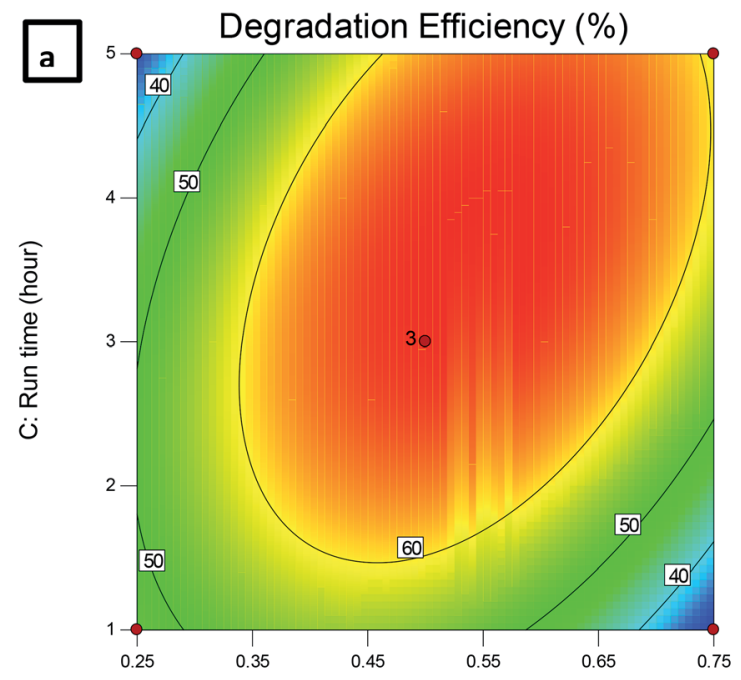

A: Pec/CS/ZnO amount (g/L)

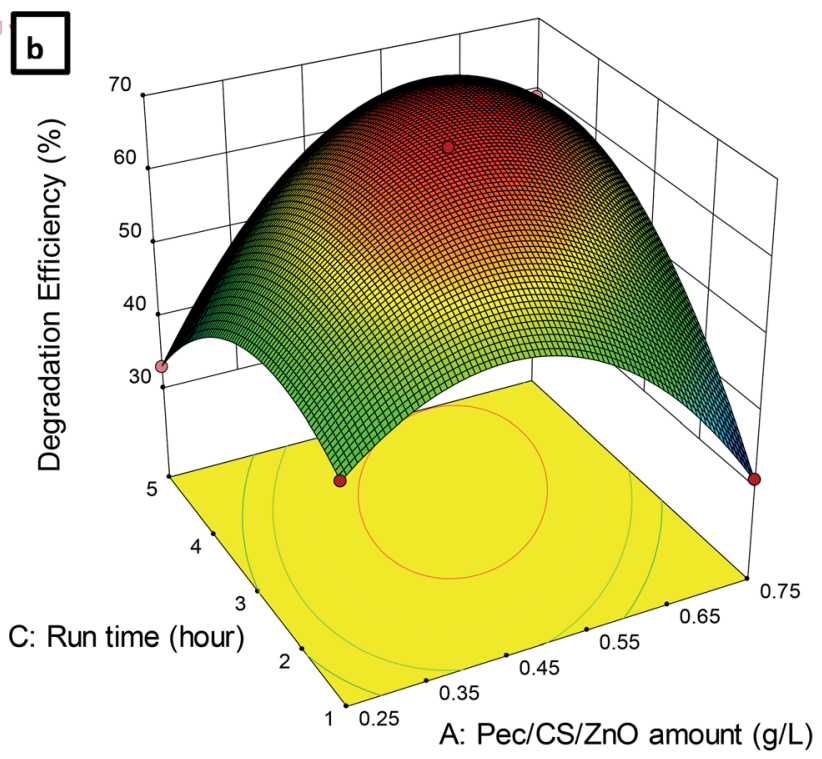

Fig. 9 (a) Contour plot and (b) 3D plot showing the effect of Pec/CS/ $\mathrm{ZnO}$ amount and run time on CBZ degradation efficiency.

observed at all the studied pHs. Thus, based on the obtained results $0.5 \mathrm{~g} \mathrm{~L}^{-1} \mathrm{Pec} / \mathrm{CS} / \mathrm{ZnO}$ nanocomposite, $\mathrm{pH} 4$ and 3 hour run time were selected as the optimum conditions required for the remediation of $\mathrm{CBZ}$ in aqueous solutions with $\mathrm{CBZ}$ concentrations up to $10 \mathrm{mg} \mathrm{L^{-1 }}$.

3.3.3. Optimization of $\mathrm{CBZ}$ remediation process. Optimization procedure was implemented while applying a desirability approach to determine the suitable settings of the studied variables to achieve the maximum degradation of CBZ. A confirmation experiment was carried out under optimum conditions. As shown in Table 7, a value of $69.5 \%$ efficiency of CBZ degradation was obtained from the performed experiment. Such result comes in good agreement with the predicted value $69.85 \%$ confirming the validity of the proposed quadratic model 


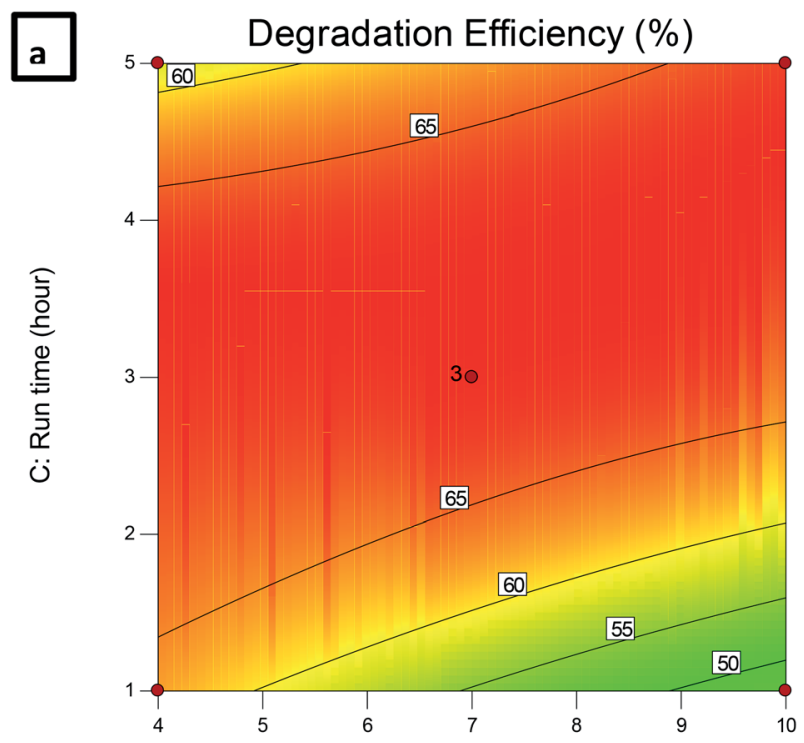

B: $\mathrm{pH}$

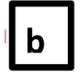

C: Run time (hour)

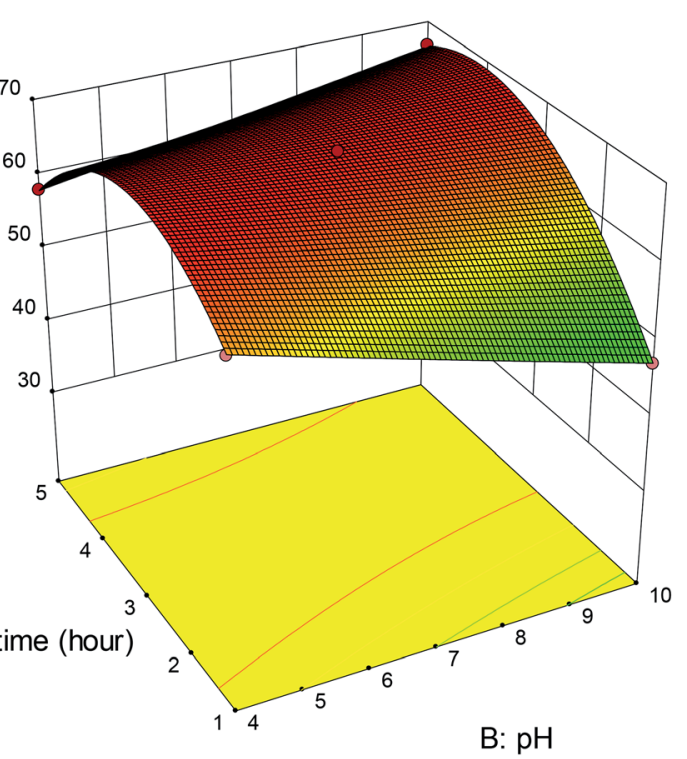

Fig. 10 (a) Contour plot and (b) 3D plot showing the effect of $\mathrm{pH}$ and run time on $\mathrm{CBZ}$ degradation efficiency.

to simulate the remediation of CBZ via a synergistic adsorption/ photocatalytic technique.

\subsection{Mechanism of $\mathrm{CBZ}$ remediation}

For complete understanding of the mechanism of CBZ remediation, a series of reference experiments was carried out under the optimum conditions obtained by BBD using dark/Pec/CS/ $\mathrm{ZnO}, \mathrm{UV}, \mathrm{UV} / \mathrm{ZnO}$ and UV/Pec/CS/ZnO. The efficiency of CBZ degradation under these conditions is illustrated in Fig. 11. The adsorption experiment was performed in the dark in the presence of $0.5 \mathrm{~g} \mathrm{~L}^{-1} \mathrm{Pec} / \mathrm{CS} / \mathrm{ZnO}$ nanocomposite and $10 \mathrm{mg} \mathrm{L}^{-1}$ $\mathrm{CBZ}$ at $\mathrm{pH}$ 4.0. After 3 hours, the degradation efficiency with
Table 7 The optimized CBZ degradation with observed and predicted response values ${ }^{a}$

\begin{tabular}{|c|c|c|}
\hline Independent variable & & $\begin{array}{l}\text { Optimized } \\
\text { level }\end{array}$ \\
\hline$X_{1}:$ Pec/CS/ZnO amount $\left(\mathrm{g} \mathrm{L}^{-1}\right)$ & & 0.5 \\
\hline$X_{2}: \mathrm{pH}$ & & 4 \\
\hline$X_{3}:$ run time (hour) & & 3 \\
\hline Over all desirability & & 1.000 \\
\hline Dependent variables & Expected & Observed \\
\hline$Y:$ CBZ degradation efficiency (\%) & $69.85 \%$ & $69.5 \%$ \\
\hline
\end{tabular}

respect to $\mathrm{CBZ}$ adsorption on the nanocomposite was found to be $59 \%$. The UV-induced photocatalytic experiments were performed in the presence of $0.5 \mathrm{~g} \mathrm{~L}^{-1} \mathrm{ZnO}$ nanoparticles and 0 and $0.5 \mathrm{~g} \mathrm{~L}^{-1} \mathrm{Pec} / \mathrm{CS} / \mathrm{ZnO}$ nanocomposite at CBZ concentration of $10 \mathrm{mg} \mathrm{L}^{-1}$ for 3 hours in direct sunlight. As shown in Fig. 11, the degradation efficiency of UV, UV/ZnO and UV/Pec/ $\mathrm{CS} / \mathrm{ZnO}$ was $54.8,61$ and $69.5 \%$ respectively. Based on the obtained results, it can be concluded that the efficiency of CBZ degradation is enhanced in the presence of $\mathrm{Pec} / \mathrm{CS} / \mathrm{ZnO}$ nanocomposite and is based on a synergistic effect of adsorption and photocatalysis processes.

Technically, the synergistic adsorption/photocatalytic process involved the adsorption of $\mathrm{CBZ}$ on $\mathrm{Pec} / \mathrm{CS} / \mathrm{ZnO}$ nanocomposite and then the photo-degradation of CBZ molecules occurred. Upon illumination of $\mathrm{ZnO}$ in $\mathrm{Pec} / \mathrm{CS} / \mathrm{ZnO}$ nanocomposite by direct sunlight, photons were absorbed and electron-hole $\left(\mathrm{e}^{-}-\mathrm{h}^{+}\right)$pairs and free radicals were created. ${ }^{39}$ Those free radicals disrupted the conjugation in the adsorbed and free CBZ molecules in solution and degraded them. ${ }^{26}$ The by-products created from degradation process were then exposed for further adsorption and photo-degradation on the surface of Pec/CS/ZnO nanocomposite. ${ }^{26}$

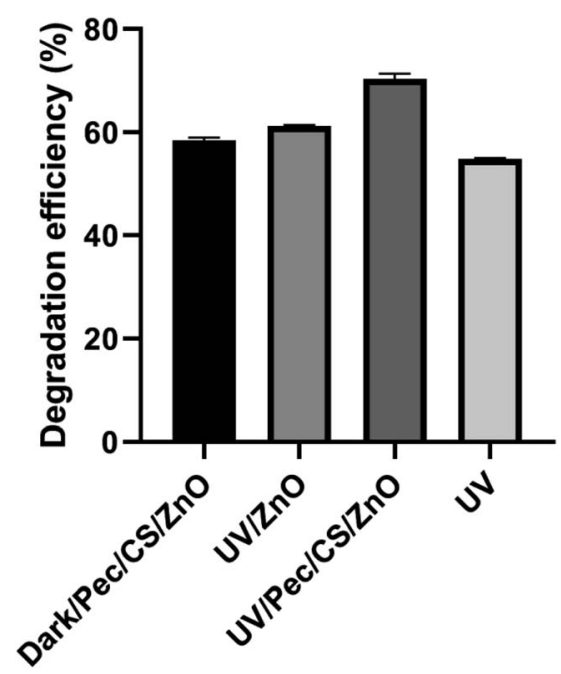

Fig. 11 Suggested mechanism of adsorption/photocatalytic process. 
Table 8 Photodegradation kinetics of CBZ reported in the literature

\begin{tabular}{|c|c|c|c|c|}
\hline Condition & $\begin{array}{l}\text { Initial }[\mathrm{CBZ}] \\
\text { concentration }\end{array}$ & $K$ (Kinetics) & $t_{1 / 2}$ & Ref. \\
\hline $\mathrm{UV} / \mathrm{TiO}_{2}$ & $10 \mathrm{mg} \mathrm{L}^{-1}$ & $0.017 \mathrm{~min}^{-1}$ & $40 \mathrm{~min}$ & 40 \\
\hline $\mathrm{UV} / \mathrm{H}_{2} \mathrm{O}_{2}$ & $42 \mu \mathrm{M}$ & $6.42 \times 10^{-4} \mathrm{~s}^{-1}$ & $17.6 \mathrm{~min}$ & 41 \\
\hline UV/whey-TiO ${ }_{2}$ NPs & $0.295 \mu \mathrm{g} \mathrm{L^{-1 }}$ & 0.92 per hour & - & 22 \\
\hline UV/whey-ZnO NPs & $0.295 \mu \mathrm{g} \mathrm{L}{ }^{-1}$ & 0.84 per hour & - & 22 \\
\hline $\mathrm{UV} / \mathrm{MWCNTs}-\mathrm{TiO}_{2}$ & $8 \mathrm{mg} \mathrm{L}^{-1}$ & $834 \times 10^{-4} \mathrm{~min}^{-1}$ & $8.3 \mathrm{~min}$ & 19 \\
\hline NUV-Vis/MWCNTs-TiO & $8 \mathrm{mg} \mathrm{L}^{-1}$ & $45 \times 10^{-4} \min ^{-1}$ & $>60 \mathrm{~min}$ & 19 \\
\hline $\mathrm{UV} / \mathrm{TiO}_{2}$ & $43 \mathrm{mg} \mathrm{L}^{-1}$ & $0.0079 \mathrm{~min}^{-1}$ & - & 42 \\
\hline Sunlight/Pec/CS/ZnO & $10 \mathrm{mg} \mathrm{L}^{-1}$ & $0.0073 \mathrm{~min}^{-1}$ & $94 \mathrm{~min}$ & This study \\
\hline
\end{tabular}

The proposed mechanism for synergistic adsorption/ photocatalysis degradation of CBZ is as follows:

$\mathrm{Pec} / \mathrm{CS} / \mathrm{ZnO}+\mathrm{CBZ} \rightarrow \mathrm{Pec} / \mathrm{CS} / \mathrm{ZnO}-\mathrm{CBZ}$ adsorbed (in sunlight)

$\mathrm{Pec} / \mathrm{CS} / \mathrm{ZnO}\left(\mathrm{h}^{+}\right)-\mathrm{CBZ}$ adsorbed $+\mathrm{H}_{2} \mathrm{O} \rightarrow \mathrm{Pec} / \mathrm{CS} / \mathrm{ZnO}\left(\mathrm{OH}^{*}\right)-$ $\mathrm{CBZ}+\mathrm{H}^{+}$

$\mathrm{Pec} / \mathrm{CS} / \mathrm{ZnO}-\mathrm{CBZ}$ adsorbed $+\mathrm{OH}^{-} \rightarrow \mathrm{Pec} / \mathrm{CS} / \mathrm{ZnO}\left(\mathrm{OH}^{*}\right)-\mathrm{CBZ}$

$\mathrm{Pec} / \mathrm{CS} / \mathrm{ZnO}\left(\mathrm{e}^{-}\right)-\mathrm{CBZ}$ adsorbed $+\mathrm{O}_{2} \rightarrow \mathrm{Pec} / \mathrm{CS} / \mathrm{ZnO}\left(\mathrm{O}_{2}{ }^{-*}\right)-$ CBZ

$\mathrm{O}_{2}{ }^{-*}$ or $\mathrm{OH}^{*}+\mathrm{CBZ}-\mathrm{Pec} / \mathrm{CS} / \mathrm{ZnO} \rightarrow$ intermediate product $\rightarrow$ degraded product + free $\mathrm{Pec} / \mathrm{CS} / \mathrm{ZnO}$ for reuse

The kinetics of CBZ degradation using Pec/CS/ZnO nanocomposite presented a linear plot as shown in Fig. S2 $\uparrow$ and was well fitted to pseudo first order equation. The value of rate constant for CBZ degradation was $0.00737 \mathrm{~min}^{-1}$ as calculated from the slope of the plot and the regression coefficient $\left(R^{2}\right)$ was 0.9992 . The $t_{1 / 2}$ was calculated to be $94.02 \mathrm{~min}$. Such kinetics of degradation is fast and suitable for wastewater treatment as compared to other reports (Table 8). Although our study showed higher $t_{1 / 2}$ than others, it has to be taken into consideration that

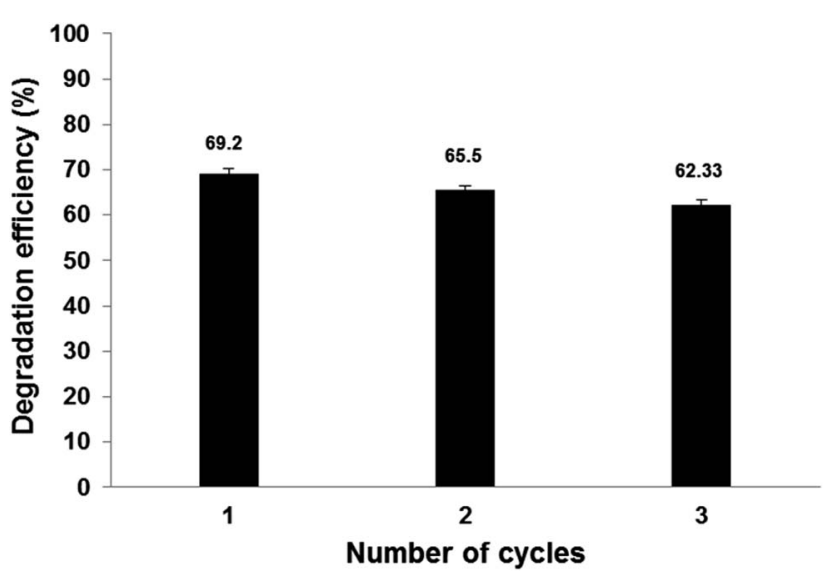

Fig. 12 The reusability of $\mathrm{Pec} / \mathrm{CS} / \mathrm{ZnO}$ nanocomposite for $\mathrm{CBZ}$ degradation and removal (initial CBZ concentration: $10 \mathrm{mg} \mathrm{L}^{-1}, \mathrm{pH}=4$ fenitrothion and nanocomposite amount $=0.5 \mathrm{~g} \mathrm{~L}^{-1}$ ). in the current study CBZ degradation was done on high initial concentration of CBZ $\left(10 \mathrm{mg} \mathrm{L}^{-1}\right)$ and sunlight was used as the source of UV light.

\subsection{Reusability of Pec/CS/ZnO nanocomposite}

As observed in Fig. 12, Pec/CS/ZnO nanocomposite shows a low degradation profile. The loss of degradation efficiency between the first and the second use is negligible, although it increases in the third use most likely due to the loss of the photocatalyst ions from the composite matrix. ${ }^{41}$ Nevertheless, after three hours of treatment, the degradation efficiency of CBZ was slightly decreased after the third reuse which proves that Pec/ $\mathrm{CS} / \mathrm{ZnO}$ nanocomposite has potential stability and reusability for CBZ degradation and removal.

\subsection{Application on synthetic wastewater samples}

The efficiency of Pec/CS/ZnO nanocomposite for CBZ remediation in the presence of other contaminants was tested as a trial for large scale wastewater treatments. Acetaminophen was selected as model pharmaceutical contaminant. Samples were prepared by spiking distilled water with $10 \mathrm{mg} \mathrm{L}^{-1} \mathrm{CBZ}$ and different concentration of acetaminophen ranging between 0 and $15 \mathrm{mg} \mathrm{L}^{-1}$. As shown in Fig. 13, Pec/CS/ZnO nanocomposite showed successful degradation of CBZ with an efficiency ranging between $58.57-69.30 \%$ at different levels of acetaminophen. Noticeably, the increase in acetaminophen concentration from 0 to $15 \mathrm{mg} \mathrm{L}^{-1}$ led to a slight decrease in the

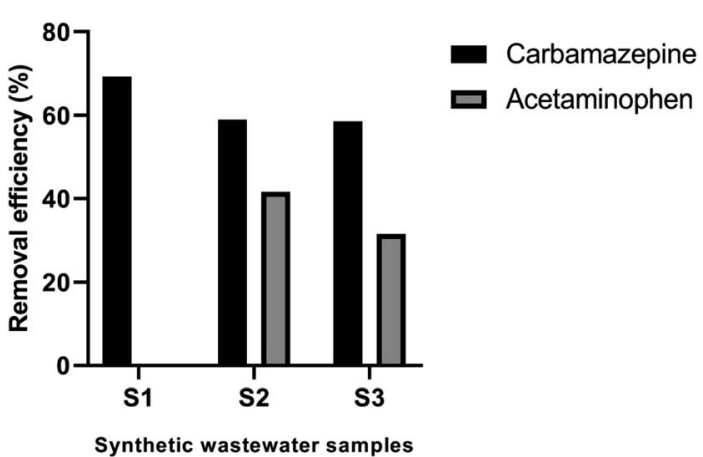

Fig. 13 Efficiency of CBZ degradation by Pec/CS/ZnO nanocomposite in synthetic wastewater samples. 
degradation efficiency of CBZ up to $10 \mathrm{mg} \mathrm{L}^{-1}$ acetaminophen concentration then there was stabilization in CBZ degradation with further increase in acetaminophen concentration. Such behavior could be due to the fact that acetaminophen molecules $\left(\mathrm{p} K_{\mathrm{a}}=9.38\right)$ might have competed with CBZ for the active sites on Pec/CS/ZnO nanocomposite thus decreasing the portion of CBZ adsorbed on the nanocomposite surface. Hence the photocatalytic degradation of CBZ was decreased. Nevertheless, the steadiness in CBZ degradation despite the addition of acetaminophen at concentrations higher than $10 \mathrm{mg} \mathrm{L}{ }^{-1}$ could be attributed to the higher adsorption capacity of $\mathrm{Pec} / \mathrm{CS} / \mathrm{ZnO}$ nanocomposite to CBZ than to acetaminophen. Thus the competition between the two molecules on the nanocomposite active sites had an extent where any additional molecules of acetaminophen were not adsorbed and left free in the solution leading to unaffected CBZ degradation efficiency.

\section{Conclusion}

The performance of Pec/CS/ZnO nanocomposite has been evaluated for a synergistic adsorption/photocatalytic degradation of CBZ. The characterization study showed that Pec/CS/ ZnO nanocomposite was an excellent choice for CBZ remediation due to its porous surface, different functionalities and high surface area. The employment of BBD to optimize the operating conditions for $\mathrm{CBZ}$ remediation using $\mathrm{Pec} / \mathrm{CS} / \mathrm{ZnO}$ nanocomposite was very successful. All the investigated factors showed a significant influence on the studied response. The quadratic model developed for CBZ degradation was significant with very low $p$-values $(p<0.0001)$. The optimum conditions obtained by the model included $0.5 \mathrm{~g} \mathrm{~L} \mathrm{~L}^{-1}$ of Pec/CS/ZnO nanocomposite, $\mathrm{pH}$ of 4 and run time of 3 hours. The predicted values for the efficiency of CBZ degradation (\%) created by the model were in good agreement with the experimental results with desirability of $100 \%$, and $69.5 \%$ degradation efficiency. The presence of other pharmaceutical contaminants like acetaminophen in wastewater samples did not have a significant effect on the remediation of CBZ using Pec/CS/ZnO nanocomposite. The obtained degradation efficiency was almost constant at different concentrations of acetaminophen.

Moreover, the study clearly showed that Pec/CS/ZnO nanocomposite employed in a synergistic adsorption/photocatalytic degradation of CBZ was one of the appropriate methods for the remediation of serious pharmaceutical contaminants as CBZ. Further understanding and elaboration of the kinetics, mechanisms, intermediates produced during the degradation process will be performed in future work.

\section{Conflicts of interest}

The authors declare that there is no conflict of interest.

\section{References}

1 M. Patel, R. Kumar, K. Kishor, T. Mlsna, C. U. Pittman and D. Mohan, Chem. Rev., 2019, 119, 3510-3673.
2 M. Hachi, A. Chergui, A. R. Yeddou, A. Selatnia and H. Cabana, Biocatal. Biotransform., 2017, 35, 51-62.

3 P. E. Stackelberg, E. T. Furlong, M. T. Meyer, S. D. Zaugg, A. K. Henderson and D. B. Reissman, Sci. Total Environ., 2004, 329, 99-113.

4 X. Yuan, H. W. Jun and J. W. McCall, Anal. Lett., 2003, 36, 1197-1210.

5 C. M. Dai, X. F. Zhou, Y. L. Zhang, Y. P. Duan, Z. M. Qiang and T. C. Zhang, Environ. Technol., 2012, 33, 1101-1109.

6 A. Ghauch, H. Baydoun and P. Dermesropian, Chem. Eng. J., 2011, 172, 18-27.

7 S. Zhou, Y. Xia, T. Li, T. Yao, Z. Shi, S. Zhu and N. Gao, Environ. Sci. Pollut. Res., 2016, 23, 16448-16455.

8 O. S. Keen, S. Baik, K. G. Linden, D. S. Aga and N. G. Love, Environ. Sci. Technol., 2012, 46, 6222-6227.

9 S. Saeid, M. Kråkström, P. Tolvanen, N. Kumar, K. Eränen, J.-P. Mikkola, L. Kronberg, P. Eklund, M. Peurla, A. Aho, A. Shchukarev and T. Salmi, Catalysts, 2020, 10, 90.

10 P. Thanekar, M. Panda and P. R. Gogate, Ultrason. Sonochem., 2018, 40, 567-576.

11 I. Vergili, J. Environ. Manage., 2013, 127, 177-187.

12 E. Luster, D. Avisar, I. Horovitz, L. Lozzi, M. A. Baker, R. Grilli and H. Mamane, Nanomaterials, 2017, 7, 206.

13 X. Wei, X. Bao, J. Wu, C. Li, Y. Shi, J. Chen, B. Lv and B. Zhu, RSC Adv., 2018, 8, 10396-10408.

14 P. Somathilake, J. A. Dominic, G. Achari, C. H. Langford and J.-H. Tay, Ozone: Sci. Eng., 2018, 40, 113-121.

15 S. K. Alharbi, W. E. Price, J. Kang, T. Fujioka and L. D. Nghiem, Desalin. Water Treat., 2016, 57, 29340-29351.

16 D. C. Mcdowell, M. M. Huber, M. Wagner, U. Von Gunten and T. A. Ternes, Environ. Sci. Technol., 2005, 39, 8014-8022.

17 U. Hübner, B. Seiwert, T. Reemtsma and M. Jekel, Water Res., 2014, 49, 34-43.

18 L. Haroune, M. Salaun, A. Ménard, C. Y. Legault and J.-P. Bellenger, Sci. Total Environ., 2014, 475, 16-22.

19 C. Martínez, M. Canle L., M. I. Fernández, J. A. Santaballa and J. Faria, Appl. Catal., B, 2011, 102, 563-571.

20 D. Avisar, I. Horovitz, L. Lozzi, F. Ruggieri, M. Baker, M.-L. Abel and H. Mamane, J. Hazard. Mater., 2013, 244245, 463-471.

21 V. A. Sakkas, P. Calza, C. Medana, A. E. Villioti, C. Baiocchi, E. Pelizzetti and T. Albanis, Appl. Catal., B, 2007, 77, 135-144.

22 D. P. Mohapatra, S. K. Brar, R. Daghrir, R. D. Tyagi, P. Picard, R. Y. Surampalli and P. Drogui, Sci. Total Environ., 2014, 485486, 263-269.

23 I. Horovitz, D. Avisar, M. A. Baker, R. Grilli, L. Lozzi, D. Di Camillo and H. Mamane, J. Hazard. Mater., 2016, 310, 98107.

24 P. Calza, C. Medana, M. Pazzi, C. Baiocchi and E. Pelizzetti, Appl. Catal., B, 2004, 53, 63-69.

25 A. Zakersalehi, M. Nadagouda and H. Choi, Catal. Commun., 2013, 41, 79-82.

26 V. K. Gupta, G. Sharma, D. Pathania and N. C. Kothiyal, J. Ind. Eng. Chem., 2015, 21, 957-964.

27 L. Shi and S. Gunasekaran, Nanoscale Res. Lett., 2008, 3, 491495. 
28 N. Tian, H. Huang, Y. He, Y. Guo and Y. Zhang, Colloids Surf., A, 2015, 467, 188-194.

29 J. Fu, B. Chang, Y. Tian, F. Xi and X. Dong, J. Mater. Chem. A, 2013, 1, 3083.

30 S. C. Yan, S. B. Lv, Z. S. Li and Z. G. Zou, Dalton Trans., 2010, 39, 1488-1491.

31 H. R. Ghorbani, F. P. Mehr, H. Pazoki and B. M. Rahmani, Orient. J. Chem., 2015, 31, 1219-1221.

32 O. A. Attallah and W. Mamdouh, Int. J. Environ. Sci. Technol., 2020, 1-10.

33 O. Gulnaz, A. Kaya, F. Matyar and B. Arikan, J. Hazard. Mater., 2004, 108, 183-188.

34 D. Pathania, G. Sharma, A. Kumar and N. C. Kothiyal, J. Alloys Compd., 2014, 588, 668-675.

35 G. Magesh, G. Bhoopathi, N. Nithya, A. P. Arun and E. Ranjith Kumar, Superlattices Microstruct., 2018, 117, 3645.
36 A. Sanmugam, D. Vikraman, S. Venkatesan and H. J. Park, J. Nanomater., 2017, 2017, 8.

37 E. K. Tetteh, D. B. Naidoo, S. Rathilal, E. K. Tetteh, D. B. Naidoo and S. Rathilal, Environ. Eng. Res., 2019, 24, 711-717.

38 S.-N. Nam, H. Cho, J. Han, N. Her and J. Yoon, Process Saf. Environ. Prot., 2018, 113, 10-21.

39 N. Tafreshi, S. Sharifnia and S. Moradi Dehaghi, Process Saf. Environ. Prot., 2017, 106, 203-210.

40 A. Jelic, I. Michael, A. Achilleos, E. Hapeshi, D. Lambropoulou, S. Perez, M. Petrovic, D. Fatta-Kassinos and D. Barcelo, J. Hazard. Mater., 2013, 263, 177-186.

41 S. Teixeira, P. M. Martins, S. Lanceros-Méndez, K. Kühn and G. Cuniberti, Appl. Surf. Sci., 2016, 384, 497-504.

42 T. E. Doll and F. H. Frimmel, Water Res., 2005, 39, 403-411. 